setting are important variables that should always be reported in biomarker research.

\section{EPV224/\#620 RADIOTHERAPY FOR PLATINUM-RESISTANT (PR) OVARIAN CANCER: SHOULD THIS BE RECONSIDERED AS A STANDARD TREATMENT OPTION?}

L Kviat*, S Banerjee, A Taylor, A George. The Royal Marsden NHS Foundation Trust, Gynaecology Unit, London, UK

\subsection{6/ijgc-2021-IGCS.295}

Objectives Radiotherapy for recurrent ovarian cancer has traditionally had a limited role due to toxicity, but recent advances enable more targeted treatments. The aims were to evaluate patterns of disease in PR ovarian cancer and investigate feasibility of radiotherapy to treat abdomino-pelvic disease.

Methods Gynaecology oncology clinic lists were retrospectively reviewed to identify 50 patients with PR ovarian cancer. Tumour location on imaging at time-point of platinum-resistance was mapped with cumulative incidences by quadrant. Three groups were defined: RT_Feasible - pelvis and lymph nodes; RT_Not Feasible -liver parenchymal metastases, gross ascites, bowel obstruction; RT_Uncertain including peritoneal disease. A dosimetric study was undertaken on ten consecutive RT-Uncertain patients producing IMRT plans delivering 30Gy/ 10 fractions with pre-defined normal structure dose constraints.

Results From 399 patients attending Nov 2019-Feb 2020, 88 (22\%) had PR disease, with 63\% confined to abdomen-pelvis. Disease was typically multi-focal with involvement of 2 or more quadrants in $84 \%$, and $88 \%$ having upper abdominal disease. Group allocation was RT_Feasible 22\%, RT_NotFeasible18\% and RT_Uncertain 60\%. There was median 5 (range 2-9) separate tumour volumes with total volume median 13.6 $\mathrm{cm}^{3}$ (range $6.5-400.3 \mathrm{~cm}^{3}$ ) resulting in planning target volumes median $458.6 \mathrm{~cm}^{3}$ (243-3077). IMRT plans encompassed tumour volumes while meeting all normal structure tolerances in $50 \%$ cases, with all plans failing for planning volumes $>1000 \mathrm{~cm}^{3}$.

Conclusions PR ovarian cancer is often widespread, but radiotherapy was feasible for $52 \%$ cases with abdomino-pelvic disease. RT could be integrated into novel treatment strategies for these patients who currently have limited options.

\section{EPV225/\#623 SAFETY OF A NEW CLOSED CO2 PERITONEAL RECIRCULATION SYSTEM (PRS) HYPERTHERMIC INTRAPERIONEAL CHEMOTHERAPY (HIPEC) AFTER INTERVAL DEBULKING SURGERY (IDS) IN ADVANCED OVARIAN CANCER (AOC) PATIENTS}

${ }^{1} \mathrm{~F}$ Murgia, ${ }^{1} \mathrm{~V}$ Carone, ${ }^{1} \mathrm{~L}$ Leone, ${ }^{2} \mathrm{~L}$ Laera, ${ }^{3} \mathrm{~F}$ Lombardi, ${ }^{3} \mathrm{I}$ Brunetti, ${ }^{2} \mathrm{G}$ Surico, ${ }^{1,4} \mathrm{~F}$ Legge* ${ }^{1}$ F. Miulli' General Regional Hospital, Gynecologic Oncology Unit, Acquaviva Delle Fonti, Italy; ${ }^{2}$ General Regional Hospital "F. Miulli", Medical Oncology, Acquaviva delle Fonti, Italy; ${ }^{3}$ General Regional Hospital "F. Miulli", Department of Anesthesiology and Intensive Care Medicine, Acquaviva delle Fonti, Italy; ${ }^{4}$ General Regional Hospital 'F. Miulli', Obstetrics and Gynecology, Acquaviva delle Fonti, Italy

\subsection{6/ijgc-2021-IGCS.296}

Objectives The avaliability of new devices aimed at improving fluid distribution with a CO2 Peritoneal Recirculation System (PRS-1.0 Combat) may be useful to further improve the clinical benefit recently showed by hypertermic intraperitoneal chemotherapy (HIPEC) after interval debulking surgery (IDS) in advanced ovarian cancer (AOC) patients. This study aimed at assessing the feasibility and perioperative outcomes of the CO2 PRS HIPEC after IDS.

Methods Over the study period 24 patients were prospectively enrolled. Patients underwent 3 neoadjuvant cycles of carboplatin AUC5 + paclitaxel $175 \mathrm{mg} / \mathrm{m} 2$ and IDS with absent residual disease. Sodium thiosulfate $(9 \mathrm{~g} / \mathrm{m} 2)$ was administered before CO2 PRS HIPEC with cisplatin $(75 \mathrm{mg} / \mathrm{m} 2$, temperature $42^{\circ} \mathrm{C}$, for 60 minutes).

Results Almost one third of patients (37,5\%) underwent ultraradical surgery with $12.5 \%$ bowel resections. Median blood loss was 500 (100-1200) $\mathrm{mL}$ and mean operative time 407.5 minutes. Median (range) intensive care unit stay and time-todischarge were $0(0-10)$ and 6 (4-17) days, respectively. We registered 3/24 (12.5\%) early serious adverse events including one acute respiratory failure and two acute kidney injuries (only one of these retained a mild chronic renal failure); one patient was readmitted within 30 days after discharge because of a dehiscence of the vaginal vault. No late adverse events were reported. Median time-to-chemotherapy was 33 days (range 22- 51).

Conclusions The CO2 PRS may improve the safety profile of HIPEC in the setting of IDS for AOC patients probably because of the more tailored drug distribution.

\section{EPV226/\#634 HYPERTHERMIC INTRAPERITONEAL CHEMOTHERAPY WITH CO2 RECIRCULATION SYSTEM (PRS) AFTER INTERVAL DEBULKING SURGERY IN ADVANCED OVARIAN CANCER (AOC): PRELIMINARY EFFICACY RESULTS FROM A PHASE II STUDY}

\begin{abstract}
${ }^{1} \mathrm{~F}$ Murgia, ${ }^{1} \mathrm{~V}$ Carone, ${ }^{1} \mathrm{~L}$ Leone, ${ }^{1} \mathrm{~V}$ Caroli Casavola, ${ }^{2} \mathrm{~A}$ Cristofano, ${ }^{1} \mathrm{~A}$ Milano ${ }^{3} \mathrm{~V}$ Delmonte, ${ }^{2} \mathrm{G}$ Surico, ${ }^{1} \mathrm{~F}$ Legge*. ${ }^{1} \mathrm{~F}$. Miulli' General Regional Hospital, Gynecologic Oncology Unit, Acquaviva Delle Fonti, Italy; ${ }^{2}$ General Regional Hospital "F. Miulli", Medical Oncology, Acquaviva delle Fonti, Italy; ${ }^{3}$ General Regional Hospital "F. Miulli", Department of Anesthesiology and Intensive Care Medicine, Acquaviva delle Fonti, Italy
\end{abstract}

\subsection{6/ijgc-2021-IGCS.297}

Objectives The addition of HIPEC to IDS in AOC has recently showed advantages in prolonging both disease-free and overall survival in AOC patients responding to neoadjuvant chemotherapy. We investigated the pattern of recurrence in a preliminary series of AOC patients treated by HIPEC with a new CO2 PRS after IDS.

Methods Twenty patients were prospectively enrolled during the study period. All patients underwent 3 cycles of neoadjuvant chemotherapy with carboplatin AUC5 + paclitaxel 175 $\mathrm{mg} / \mathrm{m} 2$ and achieved complete cytoreduction at the time of IDS. HIPEC with cisplatin $\left(75 \mathrm{mg} / \mathrm{m} 2\right.$, temperature $42^{\circ} \mathrm{C}$, for 60 minutes) was administered with a closed CO2 PRS.

Results Seven out of twenty (35\%) patients underwent ultraradical surgical procedures and $3(15 \%)$ bowel resection. After a median follow-up of 21 months (range 7-28) we registered 9 recurrences with a median time-to-recurrence of 9 months (range 5-21). Interestingly $7 / 9$ (77.8\%) recurrences were nodal while only one patient had peritoneal relapse (5\%) and one more recurred with pleural disease. Only 2 patients died from relapsed disease.

Conclusions Our preliminary efficacy data showed that peritoneal recurrence in AOC may be potentially reduced by the 
implementation of HIPEC with the CO2 PRS, probably due to a better drug distribution in the peritoneal cavity. This is of critical importance given that pattern of recurrence as carcinomatosis is undoubdtely associated with unfavourable outcome.

\section{EPV227/\#79 OVARIAN CANCER INCIDENCE AFTER BILATERAL SALPINGO-OOPHORECTOMY IN WOMEN WITH HISTOLOGICAL PROVEN ENDOMETRIOSIS OR ADENOMYOSIS}

${ }^{1} \mathrm{M}$ Hermens ${ }^{*},{ }^{2} \mathrm{~A}$ Van Altena, ${ }^{3} \mathrm{~J}$ Bulten, ${ }^{1} \mathrm{H}$ Van Vliet, ${ }^{4} \mathrm{~A}$ Siebers, ${ }^{1} \mathrm{R}$ Bekkers. ${ }^{1}$ Catharina Hospital, Obstetrics and Gynaecologt, Eindhoven, Netherlands; ${ }^{2}$ Radboudumc, Obstetrics and Gynaecology, Nijmegen, Netherlands; ${ }^{3}$ Radboudumc, Pathology, Nijmegen, Netherlands; ${ }^{4}$ PALGA, Pathology, Houten, Netherlands

\subsection{6/ijgc-2021-IGCS.298}

Objectives Endometriosis is associated with an increased ovarian cancer incidence. Surgical treatment of endometriosis might reduce this risk. Therefore, we assessed the ovarian cancer incidence in women with endometriosis after bilateral salpingo-oophorectomy (BSO).

Methods All women with histological proven endometriosis between 1990 and 2015 in the Netherlands were identified. Women with a BSO without ovarian cancer at time of surgery were selected as cases $(n=14,410)$. We selected two control cohorts; 1) women with histological proven endometriosis without BSO or with ovarian cancer at time of BSO $(n=115,323)$, and 2) women with a benign dermal nevus $(n=132,654)$. Histological diagnoses of ovarian or extra-ovarian cancers were retrieved. Incidence rate ratios (IRR) were estimated for (extra) ovarian cancer.

Results We identified $13(0.09 \%)$ extra-ovarian cancers in the BSO cohort and 2,036 (1.8\%) and $471(0.4 \%)$ ovarian cancers in the endometriosis and nevus cohort, respectively. We found an age-adjusted IRR of 0.02 (95\%CI 0.01-0.04) when the BSO cohort was compared with the endometriosis cohort and an age-adjusted IRR of 0.20 (95\%CI 0.11-0.37) when comparing the BSO to the nevus cohort (table 1 ). Median age at cancer diagnosis was 61 (IQR 56-74) in the BSO cohort, 55 (IQR 48-63) in the endometriosis cohort and 58 years (IQR 51-65) in the nevus cohort (both $\mathrm{p}<0.05$ ).

Conclusions We found a significantly reduced (extra-)ovarian cancer incidence in women with endometriosis and a

Abstract EPV227/\#79 Table 1 Estimated incident rates per 100,000 person-years, crude incidence rate rations, and ageadjusted incidence rate ratios of ovarian cancer in women with endometeriosis with BSO compared to 1) women with endometriosis without BSO (or BSo at time of ovarian cancer) and 2) women with a being dermal nervus

\begin{tabular}{|c|c|c|c|}
\hline & $\begin{array}{c}\text { Incid ence rate per } 100,000 \\
\text { person-years }(95 \% \text { CJ) }\end{array}$ & $\begin{array}{c}\text { Crude incidence rate } \\
\text { ratios }(95 \% 6 \mathrm{CI}) \\
\end{array}$ & $\begin{array}{l}\text { Age-adjusted incidence } \\
\text { rate ratios }(95 \% \mathrm{CI})\end{array}$ \\
\hline BSO & $6.47(3.75-11.14)$ & - & - \\
\hline $\begin{array}{l}\text { Endometriosis } \\
\text { without BSO }\end{array}$ & $118.40(113.33-123.57)$ & $0.05(0.03-0.09)$ & $0.02(0.01-0.04)$ \\
\hline Nevus & $23.21(21.20-25.40)$ & $0.28(0.15-0.48)$ & $0.20(0.11-0.37)$ \\
\hline
\end{tabular}

BSO when compared to both controls with endometriosis without BSO, and controls without histological proven endometriosis.

\section{EPV228/\#80 INCREASED INCIDENCE OF OVARIAN CANCER IN BOTH ENDOMETRIOSIS AND ADENOMYOSIS}

${ }^{1} \mathrm{M}$ Hermens ${ }^{*},{ }^{2} \mathrm{~A}$ Van Altena, ${ }^{3} \mathrm{~J}$ Bulten, ${ }^{1} \mathrm{H}$ Van Vliet, ${ }^{4} \mathrm{~A}$ Siebers, ${ }^{1} \mathrm{R}$ Bekkers. ${ }^{1}$ Catharina Hospital, Obstetrics and Gynaecologt, Eindhoven, Netherlands; ${ }^{2}$ Radboudumc, Obstetrics and Gynaecology, Nijmegen, Netherlands; ${ }^{3}$ Radboudumc, Pathology, Nijmegen, Netherlands; ${ }^{4}$ PALGA, Pathology, Houten, Netherlands

\subsection{6/ijgc-2021-IGCS.299}

Objectives Recently we conducted a study in which we found an increased association of ovarian cancer in women with endometriosis. Analyses showed that the cohort included both women with endometriosis externa and adenomyosis. Therefore, in the present study we assessed the association between endometriosis and/or adenomyosis and ovarian cancer.

Methods We identified all women with histological proven endometriosis (51,544 women) and/or adenomyosis (85,015 women) from the Dutch pathology database (1990-2015) and matched them with women with a benign dermal nevus (132,654 women). Histology results for ovarian cancer were retrieved. We estimated crude and age-adjusted incidence rate ratios (IRR) for ovarian cancer.

Results We found 1,017 (2.0\%), 1,284 (1.5\%) and 471 $(0.4 \%)$ ovarian cancer cases in the endometriosis, adenomyosis and nevus cohort, respectively. The age-adjusted IRRs were 19.75 (95\%CI 16.70-23.35) in the endometriosis cohort and 5.93 (95\%CI 4.91-7.16) in the adenomyosis cohort (table 1). The highest IRRs were found for endometrioid and clear cell ovarian cancer subtypes (table 1). Excluding the first year of follow-up did not result in a significant IRR for ovarian cancer overall but resulted in a statistically significant IRRs for clear cell and endometrioid ovarian cancer (table 1).

Conclusions We found an increased ovarian cancer incidence in both histological proven endometriosis and adenomyosis. This increased incidence was largest for endometriosis. Excluding the first year of follow-up resulted in an increased incidence for endometrioid ovarian cancer in both cohorts and clear cell ovarian cancer in the endometriosis cohort.

Abstract EPV228/\#80 Table 1 Observed number of ovarian cancers, estimated incidence rate per 100,000 person-years, crude incidence rate ratios and age-adjusted incidence. Rate ratios of ovarian cancers of women with endometriosis or adenomyosis compared with a benign dermal nevus, per ovarian cancer subtype and overall

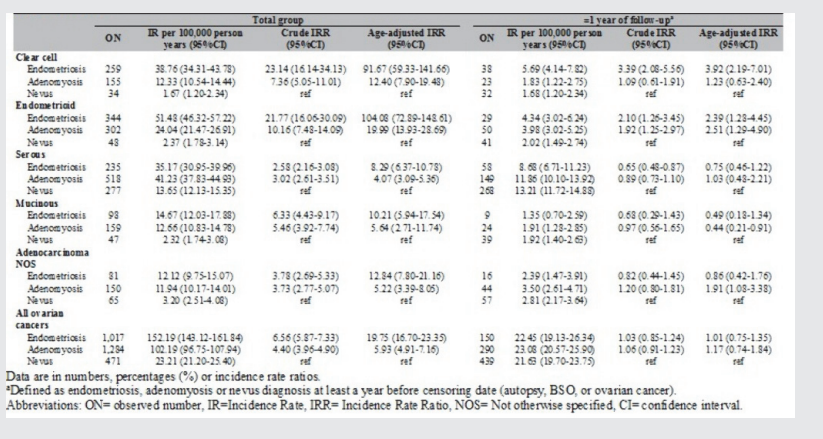

